\title{
Influence of Occupational Accidents Moderated by Occupational Health and Safety Policy Regulations on Performance of Firms in Kenya
}

\author{
Jared Otieno Otieno, Arvinlucy Onditi, Fronica Monari \\ School of Business and Economics, Jaramogi Oginga Odinga University of Science and Technology, Bondo, Kenya \\ Email address: \\ otienojaredotieno@yahoo.com (J. O. Otieno),lucionditi@gmail.com (A. Onditi), fronicak@yahoo.com (F. Monari)

\section{To cite this article:} \\ Jared Otieno Otieno, Arvinlucy Onditi, Fronica Monari. Influence of Occupational Accidents Moderated by Occupational Health and Safety \\ Policy Regulations on Performance of Firms in Kenya. Journal of Human Resource Management. Vol. 7, No. 4, 2019, pp. 99-107. \\ doi: $10.11648 /$ j.jhrm.20190704.14
}

Received: September 26, 2019; Accepted: October 31, 2019; Published: November 7, 2019

\begin{abstract}
Performance in firms is an intricate affair and remains a major agenda in the corporate world. Researches have been carried out about factors that inform performance of firms, however the extent to which occupational accidents influence performance shaped by occupational health and safety policy regulations has received limited attention in the main stream firm researches. Occupational accidents in Kenya have witnessed an annual growth of $30 \%$ based on available statistics that continues to influence performance of firms negatively. The objective of this study was to establish the influence of occupational accidents on performance of firms in Kenya. The study was founded on two theories namely: Contingency theory and General Adaptation Syndrome theory. The study was anchored on Positivism and Interpretivism Paradigms realized by explanatory research design method. The target population was 2107 with a sample size of 414. Stratified, convenient and proportionate sampling techniques were used. Data was analyzed by descriptive statistics and partial least squares structural equation modeling aided by Warp PLS. v. 5 software. The findings showed that occupational accidents moderated by health and safety policy regulations to influence performance of firms at $\beta$ eta coefficient of $(\beta=-0.27, p=0.020<0.05$ Occupational health and safety policy regulation moderation effect was at $\beta=-023, p=0.04<0.05)$. The study recommends to the government and management of firms to incorporate occupational health and safety policy regulation in firms to mitigate occupational accidents hence influence performance of firms.
\end{abstract}

Keywords: Occupational Accidents, Health and Safety, Occupational Safety Regulations, Performance

\section{Introduction}

\subsection{Background of the Study}

Occupational health and safety refers to employee physical, mental and psychosocial health at work place [12]. Occupational health and safety also refers to a state of mind and body of the employee from illness as a consequence of mental process or procedures manifest at work place [25]. Occupational accidents are therefore workplace accidents and diseases employees are exposed to due to interactions with physical, chemical, biological and psychological hazards while executing their work [15] Corporate firms will seek to incorporate health and safety measures in their operations aimed at mitigating occupational accidents for not only reducing work place absenteeism and staff turnover associated with the accidents but also influence performance [25]. The measures include and not limited to employee occupational health and safety trainings, equipment and plant maintenance and availability of protection. Occupational accidents have continued to demonstrate an alarming trend. [12] findings indicated 120 million occupational accidents annually that accounted for 210,000 deaths. Statistics according to [13] depicted an exponential rise of $40 \%$. The rise in cases of occupational accidents was attributed to lack of a sound health and safety policy regulations by firms at work place. Statistics in Indonesia during the year 2001 that involved 170,000 companies indicated five occupational deaths per day. As a matter of concern, the Indonesian government enacted a national 
policy guideline to not only reverse the negative trend, but also significantly influence performance of firms. Occupational accidents in Denmark transport sector for the period between 2010 and 2012 based on statistics with the Danish Maritime Authority registers and Radio medical occupational accidents indicated 383, 435 and 456 occupational accidents respectively for the years 2010, 2011 and 2012. Sound Korea also suffered the brunt of occupational accidents as statistics available in 2015 depicted approximately $4 \%$ rise compared to the previous year [30].

African firms have also suffered the devastating effect of occupational accidents. The researcher [33] observed sectors that depicted a high prevalence rate included agriculture, transport, construction and manufacturing sectors.

In Kenya occupational accidents indicated an average of 152 accidents per county [24]. Subsequent statistics between the year 2007 and 2011 indicated 200 occupational accidents in one county [22]. The studies in Kenya alongside a report by the Directorate of Occupational Health and Safety, Kenya note with concern that quite a number of occupational accident cases however go unreported. Busia County Government, Kenya report (2018) indicated 256 cases of occupational accidents in the county. Based on the statistics of occupational accidents in Kenya, it is glaring that there is a rising trend in occupational accidents.

\subsection{Statement of the Problem}

Corporate firms in Kenya continue to grapple with factors that impede on performance considering the harsh economic situation. An occupational accident is one of such factors that adversely affect performance of firms [13]. There is urgent need to address occupational accidents otherwise performance of firms hang on a balance. Empirical studies have been carried out about occupational accidents and performance of firms, however the extent of the influence of the relationship between occupational accident and performance of firms has received limited attention. Occupational accidents have witnessed arising trend of $30 \%$ in Kenya based on statistics between the year 2000 and 2018 [22]. This alarming trend is a matter of grave concern to both the government and the management of firms. These studies not only sort to establish the influence of occupational accidents on performance of firms but also the contingence of the moderating effect of safety policy regulations.

\subsection{Research Objective}

To establish the influence of occupational accidents moderated by occupational health and safety policy regulations on the relationship between occupational accidents and performance of firms.

\subsection{Research Hypothesis}

$\mathrm{H}_{01}$ : There is no significant influence of occupational accidents moderated by occupational health and safety policy regulations on performance of firms.

\subsection{Conceptual Framework}

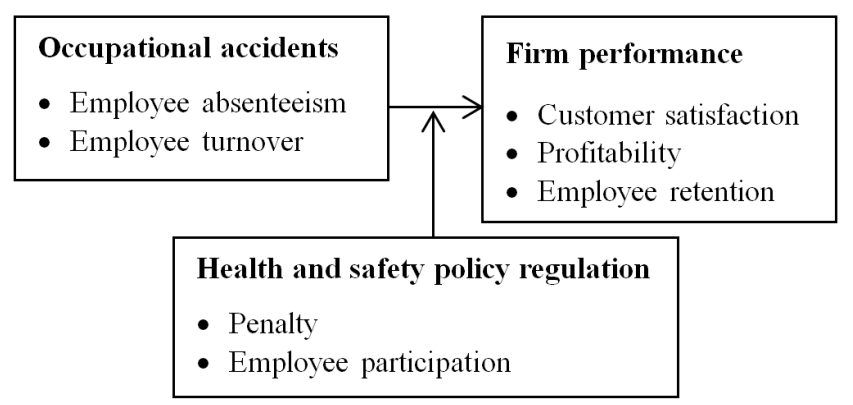

Figure 1. Conceptual Framework.

\section{Literature Review}

\subsection{Theoretical Framework}

The theoretical framework used in this study is based on General Adaptation Syndrome theory and contingency theory.

\subsubsection{General Adaptation Syndrome Theory}

General adaptation syndrome theory was founded by Selye in 1946. The theory is premised on the principle that a body automatically responds to demands put on it in three generic stages namely: Flight and freeze alarm response, Maintenance and breakdown. Flight and freeze stage is characterized by reduced resistance whereas maintenance refers to adaptation to stressful events making the individual psychologically stable and lastly breakdown stage which is about exhaustion by totally eliminating the defence mechanism. Stress is a resultant quest for the body to maintain equilibrium in what this theory refers to as homeostasis. This theory is merited for recognizing that issues of imbalances brought about by work experiences are within individuals and therefore the incumbent need to counter act in order to restore equilibrium in the individual to realize productivity and performance. The demerits of this theory is that it spotlights aspects of stress process that is not consistent with reality as demonstrated by empirical data in many studies that however observe that stress is a function of varied stressors, environmental factors and individual personal characteristics. The theory is relevant to this study because challenges of occupational accidents and unsafe work conditions and the inherent stress may in the final analysis adversely influence employee and firm performance.

\subsubsection{Contingency Theory}

Contingency theory by Fielder (1983) argues that human resource practices only impacts on organizational performance if conditioned with strategic policy. Occupational accident matters are issues of occupational health and safety practice which is a practice in human resource management. Effective occupational health and safety practice in firms that mitigates occupational accidents to realize performance of firms requires the contingence of 
vertical integration of occupational health and safety policy regulations and that is the importance the study placed on contingency theory. Contingency theory is however criticized because research has failed to consistently support the efficacy of fit or link between strategic fit and performance [5]. Other factors come to the fore in analysis of performance factors making the theory neither exhaustive nor conclusive [5].

\subsection{Empirical Literature Review}

Previous literature with regards to occupational accidents had been centered around and about magnitude of occupational accidents, prevalence rates occupational accidents, work place hazard types; work place self-reported health problem, compensable work place injuries and ill health, occupational accident severity profile, occupational accident compensation costs and challenges to occupational accident programs in firms. Majority of the literature have been based on the case studies, secondary data more so reviews of publications and occupational accident statistics. The studies have been based on occupational accidents in isolated sectors notably manufacturing, transport and construction sectors of the economy. There has been limited concern and attention by the previous literature to establish the extent of the relationship between occupational accidents and performance of firms most importantly when the relationship between occupational accidents and performance of firms is shaped by the contingency of the moderating effect of occupational health and safety policy regulation.

With regards to occupational accident compensation costs at work place for fatalities and self-reported ill health and injuries, the report [35] carried out a comprehensive review for the year 2016 and 2017 in Britain. The review report indicated that occupational accident cost was a function of human and financial costs. Human costs depicted individual quality of life for fatal injuries and loss of life. Financial costs on the other hand represented costs of loss of production and health care costs. According to the review results the total of occupational costs for the period 2016/2017 was £15.0billion shared by ill health costs and injury costs in the ratio 13:7. The review report observed that occupational accident costs was a product of quantity or number of work place injury and ill health cases by severity category and unit price per case for each category. According to the study, the unit price served as an indicator of movement of performance of entire work place health and safety program. The researcher [3] contributed to the literature on occupational accident compensation with regards to tools for economic cost analysis to be used by management in Italy. The economic cost analysis methodology tools included incident cost analysis and systematic accident cost analysis.

The researcher [8] investigated factors influencing work place accident costs based on review of 16 studies in Singapore. The study identified factors influencing occupational accident costs as loss of productivity due to the injured worker, lost productivity due to workers in the vicinity, losses due replacement of injured worker, loss of productivity due to investigation or inspection after injury, occupational accident legal fees and fines, disruption of schedule, losses associated with damaged plant and equipment and worker compensation benefits. The findings of the study revealed average direct cost of occupational accidents, indirect cost of occupational accidents and total costs of occupational accidents at $0.165 \%, 0.086 \%$ and $0.25 \%$ of the total project sum with factors namely: accident rates, project hazard levels and firm size constant. The study recommended proactive, preventive measures at work place to not only protect employees from injury but also reduce firm costs to realize performance.

The researcher [38] investigated occupational accidents in forest fire fighting employees in Australia. The study indicated forest fire as occupational hazard that exposed to dehydration and occupational accidents which negatively influenced their performance.

The researcher [37] studied sleep quantity and quality occupational accidents among fire fighters. The study took cognizant of the fact that workers in forest are subjected to fires that consequently led to multiple accidents and adverse volatile work environment that impacted negatively on their performance. According to the study sleep affected operational efficiency, physical and mental task performance. The findings indicated $40 \%$ employees suffered fire accidents due to sleep quality and quantity problem that impacted negatively on their performance.

Across sectional study in USA that relied heavily on scientific and economic business publications carried out by the study [17] investigated the value of occupational accidents and the power of prevention across a diversity of firms. The findings indicated occupational hazard exposure at work place at obesity at $15.5 \%$, fatty diets at $16 \%$, high blood pressure at $59.3 \%$, high cholesterol at $15.5 \%$, stress at $55.5 \%$ and sleep at $61.5 \%$.

The researcher [6] investigated occupational accidents due to work place incivility and resultant employee sleep deficiency based on a sample of 699 forest employees by use of emailed questionnaires. According to the study, work place incivility had far reaching repercussions as it decreased work effort, organization commitment and amount of time spent at work, reduced job satisfaction and exacerbated psycho-physical problem. The study findings indicated occupational accidents with regards to incivility influenced performance as follows: supervisor incivility $(\beta=0.48, \mathrm{t}=$ $10.12, \mathrm{p}<0.01)$ and co-worker $(\beta=0.38, \mathrm{t}=6.83)$ which were all statistically significant.

An occupational accident comparative study in Denmark by the researcher [1] investigated occupational accidents in Danish merchant fleet and naturality of sea farers. This was a study involving the transport sector whose main purpose was to examine occupational accidents reported by merchant crew ships registered by Danish Internal Ship Registration. The study provided comparative analysis of naturality differences in terms of risks and injuries of the victims. Data on occupational accidents and injuries of the victims was obtained from Danish Maritime Authority records, data bases on accidents and notifications given by the crew. The findings 
indicated accident rates of 17.5 per 100,000 person days significantly higher than East European, South East Asia and Indian Sea Man ratios of $0.53,0.51$ and 0.74 respectively. Back injury rate for Westerners was higher whereas eye injury rate was frequent among South East Asian crew. The study identified factors influencing accident rates as ship size, position and the age of the employee.

A descriptive survey [30] whose purpose was to examine relationship between occupational accidents and provision of health and safety information in Korea involved a sample size of 24527 workers, who were classified into two categories namely low and high risk exposure. The finding showed low significant relationship between health and safety information and incidences of occupational accidents in low risk group. Occupational risk increased with longer hours and the number of occupational injury was higher in workers exposed to physical, chemical and ergonomic risk factors.

The researcher [32] Investigated challenges and need for support in managing occupational accidents based on cross firm managers viewpoints in Finland. The study recognized the fact that successful occupational health and safety in firms not only improves working conditions but also health organization achieve quality work life and performance. The findings of the study revealed that quality work life is devoid is devoid of work related accidents, conflict and ill health, impaired economic performance and efficiency of organizations.

The researcher [19] Examined quantitative analysis of firms with regards to occupational health in 30 work places in Canada in across sectional study that involved diverse fields mainly plumbing, manufacture and software. The purpose of the study was to analyze employee risk exposure associated with employee depression, emotional exhaustion, wellbeing and psycho-social distress based on a sample size of 1164 employees. The findings indicated four factors explain $75 \%$ variance in firms occupational health and safety performance namely: group, hierarchical, rational and developmental.

The influence of occupational health and safety on performance of firms in Indonesia was investigated [29]. The descriptive survey involved a target population of 17,000 companies with data obtained from company publication reports. The study involved sectors that witnessed myriad cases of occupational accidents namely: construction industry, transport and mining. The study used job satisfaction as a mediating variable to the relationship between occupational health and safety and performance. The study findings indicted occupational work life influenced job satisfaction directly and performance indirectly.

The researcher [28] Studied work environment and discipline on occupational health and safety performance in a consumer goods company in Indonesia. The purpose of the research was to analyze the effects of occupational health and safety work environment the findings of which showed that work environment and employee discipline were key determinants.

Effects of industrial safety and health on employees job performance in selected cement companies in Cross River
State, Nigeria was investigated by the researcher [11]. The study was occasioned by the prevalence of occupational accidents in manufacturing sector. The findings of the survey indicated a correlation between industrial safety and employee productivity $r=0.546$, industrial safety and employee customer relationship of $r=0.316$, industrial safety and subordinate management relationship $r=0.425$ and industrial safety and employee turnover of $r=0.572$ interpreted as higher industrial safety devoid of occupational accidents the higher the employee productivity.

The researcher [22] Carried out a study whose purpose was to classify work place accidents and compensation based on occupational health and safety inherent compensation claims and occupational accidents in Kenya between the year 2007 and 2011 based on statistics in county occupational health and safety offices. The findings revealed accidents prevalence severity rates by sectors as agriculture $60 \%$, manufacture $19 \%$, electrical 5\%, wholesale and retail 5\%, transport $2 \%$ and construction $2 \%$.

A study of influence of occupational health and safety on performance in the context of manufacturing firms was carried out by the researcher [18]. This study was informed by the many cases of occupational accidents cases in the manufacturing sectors in Kenya. The study used a convenient sample of manufacturing firms in Kenya. The findings of the study indicated a moderate positive relationship between occupational health and safety on performance at $\mathrm{r}=0.57, \mathrm{p}<$ 0.05 .

\section{Research Methodology}

\subsection{Research Paradigm}

The study was anchored on both interpretivism and positivism paradigm. Positivism paradigm is characterized by a detached approach to research that seeks to find facts or forces of social phenomenon in a systematic way. The approach is grounded on the notion that studies in human behavior should follow the format of natural sciences [4]. There is objective, physical interaction between independent variable and moderating variable. Most literature on firms are inclined towards ontological and epistemological orientations of the positivist approach characterized by large samples and surveys which allows researchers some degree of control over data collection and data analysis through manipulation of study parameters and statistical procedures to produce figures and facts [21]. This study sought objective reality that was methodologically quantified and statistically tested. On the other hand interpretivism is about social construction of reality whereby researchers seek to develop subjective meanings of their experiences based on the many meanings making researchers explore complex contextual and situational views which may be historical or cultural. Interpretivism is about inductive interaction with meaning. The researcher used interview guide to assist to unravel contextual historical and cultural meanings attached to the variables of study to provide meaning to the quantitative interaction of the variables under study that can be best 
achieved by interpretivism paradigm. This study therefore unified the findings from measurements of questionnaire findings and qualitative data obtained by interviews by the human resource managers into an appropriate structure that provide the benefit of both contextual and scientific approaches as characterized by both positivism and interpretivism paradigms.

\subsection{Research Design}

Explanatory mixed method research design was used as a vehicle to realize the objectives of both interpretivism and positivism paradigm. This research design involves two phase project whereby firstly the researcher collected quantitative data, analyzes results then follows it with qualitative phase and designs questions as in interview guide based on quantitative phase that helps to explain into more details the initial quantitative results [4]. This research design method is however a challenge as it requires proper planning of questions and is also marred by demographic extremes due to respondents in both qualitative and quantitative phase having varied demographic variables [21]. This study firstly collected data from employee respondents using questionnaires manifest of phase one and then collected qualitative data from human resource managers using interview guides provide both quantitative and qualitative explanations to the interactions of variables under study.

\subsection{Target Population}

The target population was 2107 comprising of 102 Human Resource managers and 2005 employees in firms registered by the County Government of Busia (Busia County Government 2019) namely Agricultural, Construction, Transport, Retail and Manufacturing firms. The sample size was computed by Yamane formulae (1967) at 95\% confidence level. The sample size for employees was 333 respondents and that of human resource managers was 81 .

\subsection{Sampling Technique of the Study}

Stratified proportionate sampling of firms in each category (retail, agricultural, manufacturing, construction and transport) hence retail 15 firms, construction 9 firms, transport 2 firms, agricultural 1 firm and manufacturing 1 firm was carried out totaling to 28 firms. According to [23] proportionate sampling gives a fair and proportionate representation of each category. In effect a category with the highest number of employees was represented by the highest number of employees in the sample. The number of respondents drawn from each category was computed on basis of the ratio of the number of employees in every category to that of the population of employees $(\mathrm{N}=$ $2005)$ and the result multiplied by the sample size $(n=333)$ as illustrated in the table below.

Table 1. A summary of sampling technique.

\begin{tabular}{llll}
\hline Category of firms & Sample size proportion (\%) & No. of respondents & No. of Firms respondents obtained from \\
\hline Retail firms & $56 \%$ & 186 & 15 \\
Construction firms & $21 \%$ & 70 & 9 \\
Transport firms & $13 \%$ & 43 & 2 \\
Agricultural firms & $3 \%$ & 10 & 1 \\
Manufacturing firms & $7 \%$ & 24 & 1 \\
Total & $100 \%$ & 333 & 28 \\
\hline
\end{tabular}

The number of respondents for a particular category was proportionately assigned to the sampled firms within that category and all the respondents picked by simple random sampling. The 28 firms were picked based on purposive sampling, respondents in each of the 28 firms by simple random sampling while the 81 human resource managers was realized by purposive sampling technique

\subsection{Research Instrument}

Structured self-administered questionnaires were used as they capture as more information as possible. [23]. Personal interview with the Human Resource manager respondents using interview guide was used. Interviews are most appropriate for members of management who are a few in number and are capable of eliciting in depth perspectives of the subject matter in question [4]. Personal interview helps researcher create rapport with the respondents and provide guidance so that response generated are relevant and within the subject matter [23]. Document analysis involved some documents like minutes, memos, website pages, employee medical records and accident incident reports.

Structured self-administered questionnaires, document analysis and interview guides were used to collect data from the 333 employee respondents with interview guide used to collect data from the 81 human resource managers. Interview guide is most appropriate for members of management who are always few in numbers and are capable of eliciting in-depth perspectives of the subject matter in question [4].

\subsection{Data Collection Procedure}

The researcher obtained permission from Jaramogi Oginga Odinga University of Science and Technology on approval of the proposal to proceed on for data collection. In conformity with the Government policy, permission was obtained from the National Commission for Science and Technology and Innovation (NACOSTI, Kenya). The researcher engaged Human Resource manager respondents whereas two research assistants collected data from the rest of the employee respondents using questionnaires. The interview guide focused on thematic areas namely occupational accidents, Health and safety policy regulations and performance of firms. Interviews provided in depth data necessary for qualitative data [23]. It allowed researcher to clarify questions, probe 
answers, develop rapport and extract sensitive information. Qualitative data was then transcribed carefully read line by line, segmented to meaningful analytical units (codes). The coding depicted marking of segments of data with symbols, descriptive words or category names [4]. Document analysis of medical records, accident incident report, and public documents like memos, minutes, personal letters, website pages and accident incident reports of the firms were also used.

\section{Data Analysis Presentation Discussions}

\subsection{Reliability of Research Instrument}

Occupational accidents as an independent variable had a reliability coefficient of 0.841 , health and safety policy regulation of 0.879 and performance of firms 0.816 . All the study variables had a reliability coefficient of more than 0.7 threshold stipulated by [16] hence are acceptable.

\subsection{Validity of Research Instrument}

Validity was measured using average variance extracted (AVE'S) and findings indicated validity indices of 0.722 for occupational accidents, 0.885 for health and safety policy regulations and 0.627 for firm performance. Validity index of AVE 0.5 is acceptable according to the threshold [16] hence the validity indices in this study satisfied the standard.

\subsection{Measurement of Influence of Occupational Accidents of Performance of Firms}

$27.8 \%$ respondents agreed to a great extent that occupational accident induced absenteeism influenced performance of firms, $29.3 \%$ agreed to some extent, $7 \%$ were not sure whether absenteeism influenced performance, $19.8 \%$ agreed that absenteeism influenced to a small extent and $15.8 \%$ respondents were of the opinion that occupational accidents associated absenteeism did not at all influence performance as indicated in table 2 .

Table 2. Measurement of influence of occupational accidents of performance of firms.

\begin{tabular}{|c|c|c|c|c|c|}
\hline Indicator & To great extent & To some extent & Not sure & To small extent & Not at all \\
\hline Absenteeism & $27.8 \%$ & $29.3 \%$ & $7 \%$ & $19.8 \%$ & $15.8 \%$ \\
\hline Employee turn over & $35.9 \%$ & $18.3 \%$ & $11 \%$ & $21.61 \%$ & $12.8 \%$ \\
\hline
\end{tabular}

\subsection{Measurement of Moderating Effect of Occupational Health and Safety Policy Regulations}

Based on respondents' responses with regards to indicators of occupational health and safety policy namely: penalty for violation and employee participation, $29.3 \%$ agreed to a greater extent that indeed penalty for violation with respect to occupational health and safety policy regulations influenced the relationship between occupational accidents and performance, $32.6 \%$ agreed that penalty for violation influenced to some extent, $11 \%$ were not sure of the influence of penalty for violation, $20.5 \%$ had the opinion that penalty for violation influenced to a small extent and $4.4 \%$ had the opinion that penalty for violation did not influence at all.

About employee participation on occupational health and safety policy regulation matters $47.6 \%$ respondents agreed to a great extent that it indeed influenced the relationship between occupational accidents and performance of firms. $19.4 \%$ however agreed to some extent, $4 \%$ were not sure whether employee participation influenced the said relationship, $15.8 \%$ had the opinion that the influence was to a small extent whereas $2.5 \%$ respondents did not at all agree that employee participation on occupational health and safety policy regulation matters influenced the relationship between occupational accidents and performance of firms.

Table 3. Measurement of moderating effect of occupational health and safety policy regulations.

\begin{tabular}{|c|c|c|c|c|c|}
\hline Indicator & To great extent & To some extent & Not sure & To small extent & Not at all \\
\hline Penalty for violation & $29.3 \%$ & $32.6 \%$ & $11 \%$ & $20.5 \%$ & $4.4 \%$ \\
\hline Employee participation & $47.6 \%$ & $19.4 \%$ & $4.0 \%$ & $15.8 \%$ & $2.5 \%$ \\
\hline
\end{tabular}

\subsection{Hypotheses Testing}

Hypothesis 1: There is no significant influence of occupational accidents moderated by health and safety policy regulation on performance of firms in Kenya.

From the results occupational accidents significantly influenced performance of firms in Kenya at $\beta=-0.27, p=$ $0.01<0.05$. It therefore followed that the null hypothesis was rejected and alternate hypothesis accepted. Based on the findings a unit increase in occupational accident decreases performance by -0.27 and a unit decrease in occupational accidents increases performance of firms by 0.27 .

The study findings with regards to the variable of occupational accident on performance of firms based on path analysis indicated that occupational accidents significantly negatively influence performance of firms in Kenya with a coefficient of $(\beta=-0.27 \mathrm{P}=0.001<0.05)$. The findings is supported by among other studies: $[14,18]$ observed in their findings that occupational accidents negatively influence performance since they compromise product service quality, inhibits employee performance affects employee presentitiseem and inform cases of employee turnover.

The excerpts from the interviews are characterized by connotations that bear testimony to the negative influence of occupational accidents on performance of firms. They include: occupational accidents disrupt operations, employees are demoralized, employees are incapacitated to work and the likes. Warp PLS estimation results indicated that without the 
influence of health and safety policy regulation Occupational accidents directly influence performance of firms at $(\beta=-0.28$, $p=0.01<0.05)$ which is also significant. The researcher [20] observes that the worst influence of occupational accidents is its correlation with product service quality that stands at $\beta=$ 0.737. The study therefore recommended strong policy and practice framework on occupational health and safety to help check the situation.

Table 4. Hypothesis: influence of occupational accidents moderated by health and safety policy regulations on performance.

\begin{tabular}{llll}
\hline Model & Beta coefficient & P value & Standard error \\
\hline Occupational accidents (OA) & -0.27 & 0.01 & 0.059 \\
\hline
\end{tabular}

Warp PLS Structural Model Estimation Results

Figure 2 about Warp PLS structural model results includes study variables namely: Occupational accidents (Independent variable) and performance of firms (Dependent variable). Occupational accidents are denoted by (OccAcc), health and safety policy regulation by (HeSafPol) and performance of firms (PerFirm). The model indicates direct relationship between occupational accidents and performance of firms without the effect of health and safety policy regulation moderation. The model shows the estimation of relationship of study variables using their ßeta coefficients and corresponding $\mathrm{p}$ - values depicting their level of significance.
Significance level of 0.05 and below were considered ideal and accepted. The model estimation for direct relationship of variables indicated that the relationship between occupational accidents and performance of firms is at $(\beta=-0.28, p=0.01<$ 0.05 ) hence significant. The finding would be interpreted to mean that without the moderation of health and safety policy regulation occupational accidents increase decreases performance of firms and decrease increases performance of firms. Occupational accidents thus decrease a unit increase in performance by 0.28 . The model also indicates that occupational accidents explains $8 \%$ variance in performance as signified by $\mathrm{R}^{2}=0.08$.

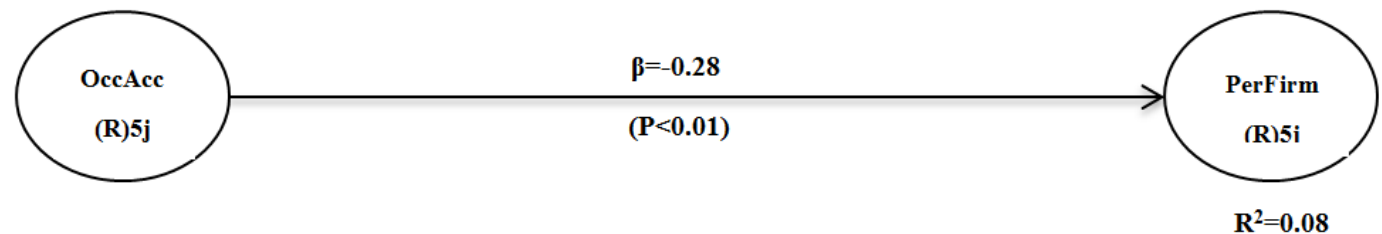

Figure 2. Structural model estimation results for direct influence of occupational accidents.

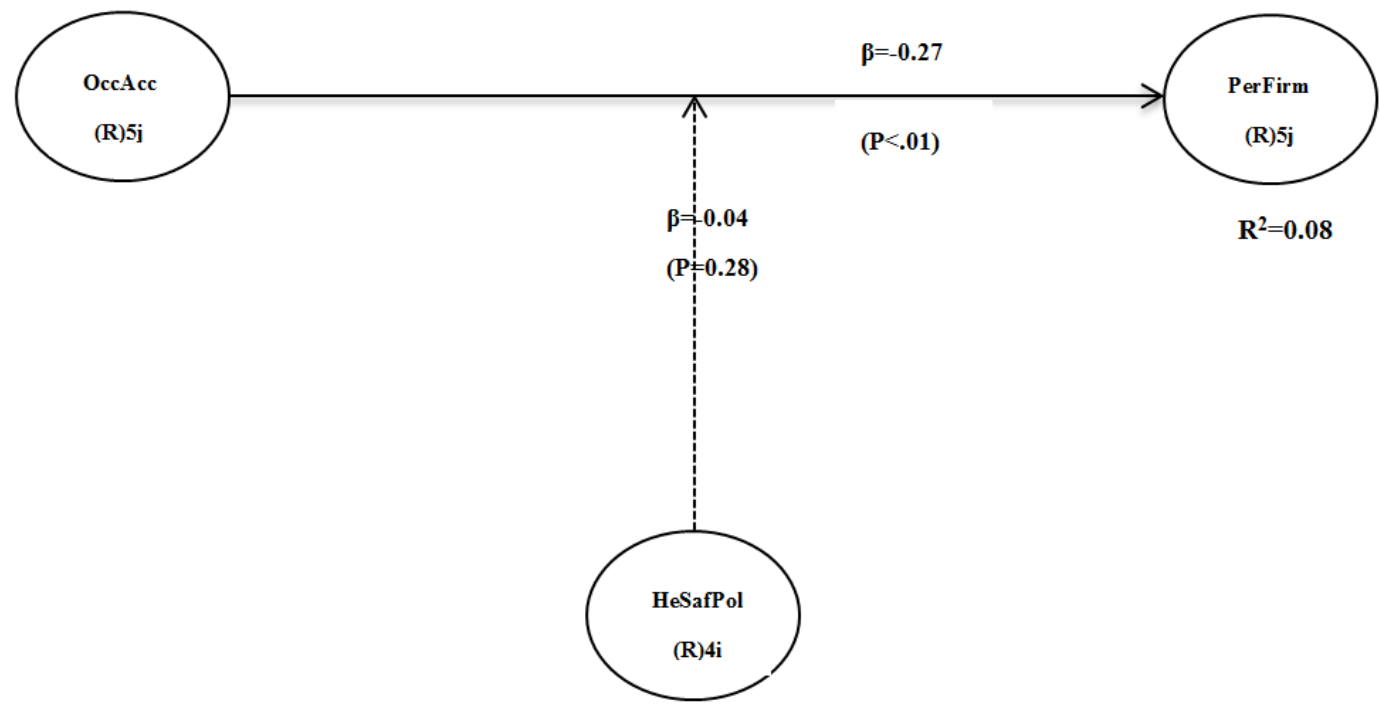

Figure 3. Structural model estimation results with the effect of the moderator variable.

Figure 3 illustrates a relationship involving three variables namely occupational accidents (Independent variable), Health and safety policy regulation (Moderator variable) and performance of firms (Dependent variable). The relationships amongst the variables are estimated using their ßeta coefficients with their corresponding $\mathrm{p}$ - values depicting their level of significance. The model indicates that occupational accidents moderated by health and safety policy regulation influences performance of firms at $(\beta=-0.27, p=0.01<0.05)$ therefore significant. From the estimation results it can be interpreted that occupational accidents moderated by health and safety policy regulation negatively influences performance. It follows that as occupational accidents increase, performance decreases and that occupational accident decreases a unit increase in performance by -0.27 . The effect of health and safety policy regulation on the relationship between occupational accidents and performance is at $(\beta=-0.23, p=0.04<0.05)$ which is significant. The 
result on moderation demonstrates that health and safety policy regulation moderates the relationship between occupational accidents and performance of firms negatively. The $\mathrm{R}^{2}=0.08$ also depicts that occupational accidents moderated by health and safety policy regulation explains $8 \%$ variance in performance of firms.

\section{Summary of Findings}

The objective was to establish the influence of occupational accidents on performance of firms in Kenya. This was based on the hypothesis:

$\mathrm{H}_{01}$ There is no significant influence of occupational accidents on performance of firms in Kenya.

The analysis based on structural model estimation results indicated that occupational accidents significantly influenced performance of firms at $(\beta=-0.27 \mathrm{P}=0.01<0.05)$ hence significant. From the findings a conclusion is drawn that firms should seek to reduce occupational accidents since it has a negative influence on performance of firms. The conclusion is consistent with the conclusions of these studies [14, 18]. On indicators of occupational accidents that is absenteeism levels and incidences of staff turnover influenced performance of firms to a great extent as indicated by $27 \%$ and $45 \%$ respondents respectively. $35 \%$ respondents observed that occupational accidents influenced turn over and performance of firms to a great extent.

\section{Conclusion and Recommendations}

An occupational accident is one of the factors that statistically and significantly influence performance of firms. From this study it can be argued that if occupational accidents are reduced in firms, employees would be assured of their health and safety at work place hence influence performance of such firms positively. This is in agreement with general adaptation syndrome theory that imbalances brought about by work experiences are within individuals and therefore it is incumbent for the individual and the environment to address the imbalance to restore equilibrium. The resultant homeostasis or body equilibrium not only influences employee productivity but also performance of firms. The findings of the study imply that an occupational accident is a major cause of negative performance of firms. From the study findings it can be concluded that occupational accidents induced absenteeism and employee turnover adversely affect performance of firms. Majority of the employees in the firms studied have a feeling that occupational accidents explain employee absenteeism and turn over and that implies that management of firms should be pre-occupied with measures and programs aimed at mitigating this phenomenon. Further to this the study finding indicates that occupational health and safety policy regulations in firms should be strengthened most importantly with regards to its inherent indicators namely: penalty for violation and employee participation. Majority of the employees studied felt that penalty for violation and employee participation are pertinent in addressing occupational accidents that in the final analysis translate to employee productivity and performance of firms. [36] alluded to the fact a sound occupational health and safety regulation should include a component penalty for violation as regulation without compliance is dysfunctional.

A clear health and safety policy regulation should also involve a component of employee participation that not only inculcates employee citizenship, reduces absenteeism, turnover, but also has a direct effect of productivity and performance. Emphasis should be laid by human resource management practitioners on employee empowerment on issues of decision with respect to occupational health and safety. This would in the long run reduce occupational accidents and influence performance of firms. The government of Kenya should also play an oversight role in streamlining occupational health and safety policy matters in firms. The government can play this oversight role by among other measures, providing technical, financial and material support to the Directorate of Occupational Health and Safety Department.

\section{References}

[1] Adam, B., Rasmussen, H. B, Pedersen, R. N. F \& Jepsen, J. R (2014) Occupational accidents in the Danish Merchant Fleet and the naturality of Sea farers. Journal of Occupational Medicine and Technology, 9 (35) 1-8.

[2] Adam, W., Pope, R \& Marc Orr, R (2016) The impact of fire suppression tasks on fire fighter hydration: A critical review with consideration of the utility of reported hydration measures. Annals of Occupational and Environmental Medicine.

[3] Battaglia, M. Frey, M \& Passetti, E. (2014) Accidents at work and costs analysis, a field study in a large Italian Company Ind. Health, 52 (4) 354-366.

[4] Creswell J. W (2003). Research Design: Qualitative, Quantitative and mixed method approaches Safe, Thousand Oaks, CA.

[5] Delery, J, \& Doty, H (2000) Modes of theorizing in strategic Human Resource Management. Tests of universalistic, Contingency and configurationally performance prediction. Academy of management journal 39 [4] pp 602-835.

[6] Demsky, C. A., Fritz, C., Hammer, L. B., \& Black, A. E. [2018] Workplace incivility and employee sleep: The role of rumination and Recovery experience. Journal of occupational Health psychology. Advance online publication.

[7] Dyer, J. [2005] Human Resource Management. Evolving Roles and Responsibilities. Washington DC.

[8] Feng, Y., Zhang, S. \& Wu (2015) factors influencing workplace accident costs of building projects Saf. Sci. 72, 97-104.

[9] Garson, G. D. (2016). Partial Least Squares: Regression \& Structural Equation Models Asheboro: Associates Publishing.

[10] Hair, J. F Jr, Black, W. C, Babin B. J, Anderson, R. E, Tathan, R. L [2006] Multi data analysis. $6^{\text {th }}$ Ed New Jersey. Prentice Hall International inc. 
[11] Iheanacho, M. J. U \& Ebitu, E. T [2016] Effects of industrial safety and health on employees job performance in selected cement companies in cross power state Nigeria. International journal of Business and management Review [4] 3, 49-56.

[12] ILO (2001), Guidelines on Occupational Safety and health management systems, International labour office, Geneva 2001.

[13] International Labour Organization. (2011) Occupational Safety and Health Management systems. A tool for continual improvements: World Day for Safety and Health at Work.

[14] Kelly E. L., Kassek, E. E., Hammons L. B, Durban, M., Bray, J., Chermach, K et al (2008) Getting there from here: Resend on work formally initiatives on work family conflict and business outcomes. Academy of management annuals 2 (1) 305-349.

[15] Keynack, R., Toklin, A, Y; Elci M \& Toklu, IT (2016) Effects of health and safety practices on original contract work alienation Job Satisfaction and performance using the PLS-SEM Approach. Initial Journal of Business and Management vol 11 No 5 ISSN 1833-8119.

[16] Kock, N. (2015) Warp PLS 5.0 User Manual. Script Warp systems Loredo, Texas USA.

[17] Loeppke, R. [2008] The value of health and the power of prevention. International journa of work place health management 2 [1], 96-108.

[18] Makori, E. M, Nandi, O. M. J, Thuo, J. K and Wanyonyi, K. W (2012). Influence of occupational safety and health on performance of manufacturing firms in Western province Kenya. African Journal of History and culture (AJHC) 4 (4), 46-58.

[19] Marchand, Hainess \& Gauthier (2013). Quantitative analysis of organizational culture in occupational health research: A theory based validation in 30 work places of the organizational culture profile instrument. B. M. C Public Health 13/443.

[20] Mardiani, S. Jamaldin, T. \& Riahi L. [2013] Relationship between safety and staff performance in hospital. International journal of hospital research 2 [4], 205-214.

[21] Mollar A., \& Licker, P. S. (2005) E-Commerce adoption in developing countries: A model and instrument. Information and management Journal 42, pp 877-891.

[22] Mogambi, J. A, Mburu, C. \& Kinyua, R. (2014) can workplace Accidents classification and compensation in Kenya be used to predict level of victim satisfaction? International Journal of Innovative and Applied studies, 972-986.

[23] Mugenda, O. M. \& Mugenda, A. G. (2013). Research methods Quantitative and qualitative Approach. Nairobi. Applied Research and Training services Press.

[24] Nyakango, J [2005]. Status of occupational Health and safety in Kenya. Workshop on the safety training program, part of the congress in Beijing.

[25] Premier occupational Health core [2010] An introduction to the role of occupational Health for managers. Folkstone, England.
[26] Purcell. J. (2002) Sustaining the Human Resource and performance link in difficult times, CIPD Conference Harrogate.

[27] Purcell. J. (2004) Business strategies and Human Resource Management: uneasy Bed fellows or strategic partners? Lecture, Bath University.

[28] Putri, D. O., Triatmanto, B. \& Setijadi S [2017] The effect of occupational health and safety work environment and discipline on employee performance in a consumer goods company. International conference on Industrial and system Engineering I con/S E.

[29] Ria Mardiana Yusuf, Anis, Eliyana \& Oci Novita Sari (2012) The influence of occupational safety and health inperformance with job satisfaction as intervening variable. Study in the production employees in P. T Mahakarya Rotanindo, Gresik. American journal of economics, special issue, 136-140.

[30] Seo. J, Shin G. S, Kim M. G and Min, Y. S (2018) Relationship between occupational injuries and the provision of health and safety information. Data from $4^{\text {th }}$ Korean working conditions survey. Annals of occupational and environmental medicine 30 36 industries 58 (1), 35-59.

[31] Skinner N, Pisaniellos \& Derrian j [2010] FLAWS in our lives: Fatigue life and work strain Adelude: centre for worklife: University of South Australia.

[32] Tappura S Syvanen S \& Saurela K. L [2014] Challenges and needs for support in managing occupational health and safety from managers viewpoint. Nordic journal of working life studies 4 [3].

[33] Tawiah A. T \& Baah, K. D [2011] Occupational health and safety. Key issues and concern in Ghana. International Journal of Business and Social Sciences 2 [14]

[34] Terp-stra, D. E \& Rozell, J. [1993] The relationship of staffing practices to organizational level measures of performance, Personal Psychology [46], 27-48.

[35] UK health and safety executive (2018) costs to Britain of work place fatalities and self-reported injuries and ill health, 2016/2017.

[36] Umeokapor, N., Isaac, D., Jones, K \& Umeadi, B (2014) Enforcement of occupational safety and health regulation in Nigeria: An exploration. European Scientific journal (3), 93-104.

[37] Vincent, E. G et al [2018] sleep in wild land fire fighters. What do we know and why does it Matter. International journal of wild land fire [27], 73-84.

[38] Walker A, Pope R \& Marc Orr (2016) The impact of fire suppression tasks on fire fighters hydration: Actual review with consideration of the utility of reported hydration measures. Annals of occupational and environmental medicine.

[39] Waiganjo E. W, Mukulu.; \& Kahuri. J. (2012). Relationship between strategic Human Resource Management and firm performance of Kenya's corporate organization. 